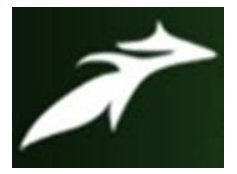

Manjula A. C. et al, International Journal of Advances in Agricultural Science \& Technology,

Vol.8 Issue.10, October-2021, pg. 7-16

\title{
Evaluation of Matured Larval Weight and Larval Duration of New Breeding Lines of Bombyx mori L
}

\author{
Manjula A. C ${ }^{1}$; Jenifer Lolita. $C^{2}$; Shubha ${ }^{3}$; Prathibha K.Y ${ }^{4}$; Keshamma. E ${ }^{5 *}$ \\ ${ }^{1}$ Department of Sericulture, Maharani's Science College for Women, Palace Road, Bengaluru, Karnataka, India \\ ${ }^{2,4}$ Department of Botany, Maharani’s Science College for Women, Palace Road, Bengaluru, Karnataka, India \\ ${ }^{3}$ Department of Botany, Government First Grade College, Vijayanagara, Bengaluru, Karnataka, India \\ ${ }^{5}$ Department of Biochemistry, Maharani's Science College for Women, Palace Road, Bengaluru, Karnataka, India \\ DOI: 10.47856/ijaast.2021.v08i10.002
}

\begin{abstract}
We planned to conduct this study with the main aim to develop bivoltine breeds for our tropical climatic conditions by using silkworm breeds with known genetic backgrounds (KA, $\mathrm{NB}_{18}$ and $\mathrm{PM}$ ) in various hybrid combinations and incorporating them over generations, followed by backcrossing and adequate selection of different generations with the objective of profitability and productivity. The isolated Bivoltin lines $\left(R_{1}\right.$ and $\left.R_{2}\right)$ were reared with their parental races at different times of the year to evaluate their stability in the expression of commercial traits. For the present breeding program, the purebred Bivoltine Kalimpong-A (KA), which spin white oval cocoons, New Bivoltine ${ }_{18}\left(\mathrm{NB}_{18}\right)$ white cocoons with rotating dumbbells and Multivoltine Pure Mysore (PM), the yellow pointed cocoons of the mulberry silkworm Bombyx mori L., Selected. One-way and three-way crosses were made using the above three breeds. The first single cross comprised KA females and PM males. The second unique cross comprised $\mathrm{NB}_{18}$ females and PM males. Selection was performed at the egg, larva, pupal, and cocoon stages over the course to determine the desired traits. The offspring of $\mathrm{F}$ from the respective crosses were backcrossed with their respective bivoltine males to improve commercial traits. Heterosis in the $\mathrm{F}_{1}$ generations of crosses, including $\mathrm{NB}_{18}$ and $\mathrm{PM}$, was determined by the mean score of the parents (MPV) and the best score of the parents (BPV). A significant test for heterosis was performed using a standard ANOVA table. Based on the results of our study, it was found that the performance of the characters, viz. The weight of mature larvae and the duration of the larvae over generations do not simply increase or decrease regularly, but fluctuate irregularly. The reason for this variation may be due to random genetic drift, sampling errors in estimating generational means, selection pressures, and environmental factors. Therefore, inbreeding variations due to random drift and sampling errors could be reduced by increasing the number sampled and selected.
\end{abstract}

Keywords: Bombyx mori L, Bivoltine, Kalimpong-A (KA), Pure Mysore (PM), Matured larval weight

\section{Introduction}

Among insects, Drosophila and the Lepidoptera silkworm, Bombyx mori, have been widely used for various experimental purposes. The silkworm B. mori has long been under the patronage of humans due to its economic value and has been the subject of research since the middle ages. These results, together with the silkworm breeding trials, did much to establish contemporary strains of silkworms of high economic value. ${ }^{1,2}$

In India, sericulture is a domestic agriculture industry that mainly provides employment to the weaker sectors of society. Due to its employment potential and profitability, its low investment costs and its high foreign exchange earnings, silkworm farming could become an important factor for the economic development of our 


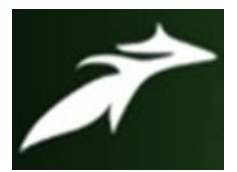

Manjula A. C. et al, International Journal of Advances in Agricultural Science \& Technology, Vol.8 Issue.10, October-2021, pg. 7-16

ISSN: 2348-1358

Impact Factor: 6.057

NAAS Rating: 3.77

country. Therefore, studies of the genetic, reproductive and biochemical aspects of the silkworm will have a direct impact on the development of the silkworm industry.

There are many species of silkworm which produce cocoons of superior filament quality and containing larger quantities of silk. Among them Bombyx mori L. of the family Bombycidae is the only species widely used for commercial rearing. India holds unique position in the world by producing all the four commercially known varieties of silk namely, mulberry, eri, Tasar and muga. India ranks second in raw silk (12,665 tonnes) production in the world (Statistical Biennial CSB 2017). The mulberry silk production in India accounts for $90.7 \%$ (28, 523 tonnes) while non-mulberry silks (eri 5060 tonnes $4.9 \%$, Tasar 2819 tonnes) $3.8 \%$ and muga (166 tonnes $0.5 \%$ ) account for $9.3 \%$ of the total raw silk production. The major share of the Indian mulberry silk production is from Karnataka accounting for 54.095\% (6214 tonnes) (Statistical Biennial CSB 2017).

Systematic breeding experiments of silkworm evolved during the past few years have enabled the breeders to synthesise desirable genotypes of known genetic constitution with a main objective of increasing the productivity and viability. Application of conventional hybridization methods with appropriate selection have contributed a great deal in increasing quality and quantity of silk. Sericulturally advanced countries such as Japan and China have achieved a remarkable breakthrough in increasing the unit production of high grade silk by evolving silkworm races suitable to their agroclimatic conditions. ${ }^{3}$ In India several attempts have been made during the last two decades to synthesise suitable, high productive bivoltine races and also multivoltine races to our tropical climatic conditions but with little success. ${ }^{4-8}$ Further, in the absence of suitable bivoltine races, the locally available multivoltine and bivoltine races are being used for the production of commercial hybrids. Therefore, the unit production and the quality of silk produced by the commercial hybrids remains poor. Hence, it is essential to synthesise better bivoltine races for commercial exploitation under tropical climatic conditions. Moreover, voltinism, moultinism, viability, productivity, resistance or susceptible to disease and tolerance to unfavourable environmental conditions assume a special importance in the efforts to synthesise suitable silkworm races.

With this scenario, the present study was undertaken to evolve bivoltine races for our tropical climatic conditions by utilizing the silkworm races of known genetic background (KA, $\mathrm{NB}_{18}$ and $\mathrm{PM}$ ) in different hybrid combinations and to inbreed them over generations followed by backcrossing and adopting appropriate selection at different generations with an objective of the viability and productivity. The isolated bivoltine lines $\left(R_{1}\right.$ and $\left.R_{2}\right)$ were reared in different seasons of the year along with their parental races to evaluate their stability in the expression of commercial characters.

\section{Materials and Methods}

\subsection{Silkworm varieties and rearing}

The pure races of bivoltine Kalimpong-A (KA) spinning oval white cocoons, New Bivoltine-18 $\left(\mathrm{NB}_{18}\right)$ spinning dumbbell white cocoons and multivoltine Pure Mysore (PM) spinning pointed yellow cocoons of mulberry silkworm Bombyx mori $\mathrm{L}$. were selected for the present breeding programme. These races were obtained from their respective seed areas and are reared in cytogenetics laboratory, Jnana Bharathi, Bangalore University.

The disease free layings were prepared as described by Narasimhanna, $(1988),{ }^{9}$ and were incubated at $251^{\circ} \mathrm{C}$ and relative humidity of $60-70 \%$. On 8th day composite layings were prepared (10-20 layings were prepared 100-200 eggs were collected from each laying). The hatched worms were reared according to the method described by Krishnaswamy (1978). ${ }^{10}$ MS variety of mulberry leaves were used in rearing. The worms were reared in mass up to III instar, after III moult 300 worms were collected in three replicates in order to evaluate the rearing performance. Standard temperature and humidity were maintained in the rearing house. 


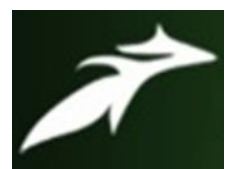

Manjula A. C. et al, International Journal of Advances in Agricultural Science \& Technology,

Vol.8 Issue.10, October-2021, pg. 7-16

ISSN: 2348-1358

Impact Factor: 6.057

NAAS Rating: 3.77

The quantitative traits such as fecundity and hatching percentage were evaluated to assess the performance breeding lines of Bombyx mori L.

\subsection{Breeding}

Single and three way crosses were made by using the above said three races. The first single cross involved KA females and PM males. The second single cross involved $\mathrm{NB}_{18}$ females and PM males. During the course of breeding selection was made at the egg, larva, pupa and cocoon stages to fix the desirable traits. Fs progenies of the respective crosses were back crossed to their respective bivoltine males to improve commercial characters.

\subsection{Evolutions of new lines $\mathbf{R}_{\mathbf{1}}$ and $\mathbf{R}_{\mathbf{2}}$}

Females of $\mathrm{KA}$ and $\mathrm{NB}_{18}$ were crossed with males of PM. The composite layings of $\mathrm{F}_{1}$ hybrid were brushed and reared under standard laboratory conditions. The selection parameters explained earlier were applied to choose the seed cocoons for the preparation of $F_{2}$ layings. The replicates showing higher pupation rate were selected for intra family selection of cocoons. Further, segregation with respect to cocoon colour and built was noticed. Only white oval in case of KAxPM and dumbbell white in case of $\mathrm{NB}_{18} \mathrm{xPM}$ qualifying the parameter of selection were choosen for breeding in subsequent generations. The females of $\mathrm{F}_{5}$ were backcrossed to the males of $\mathrm{KA}$ and $\mathrm{NB}_{18}$ respectively in both the lines and reared up to 11 generations. At the end of the $11^{\text {th }}$ generation the lines $R_{1}$ and $R_{2}$ were extracted with higher ERR than their respective better parents, with shorter larval period and with moderate cocoon productivity character in case of $R_{1}$ and $R_{2}$.

\section{Breeding Plans I and II}

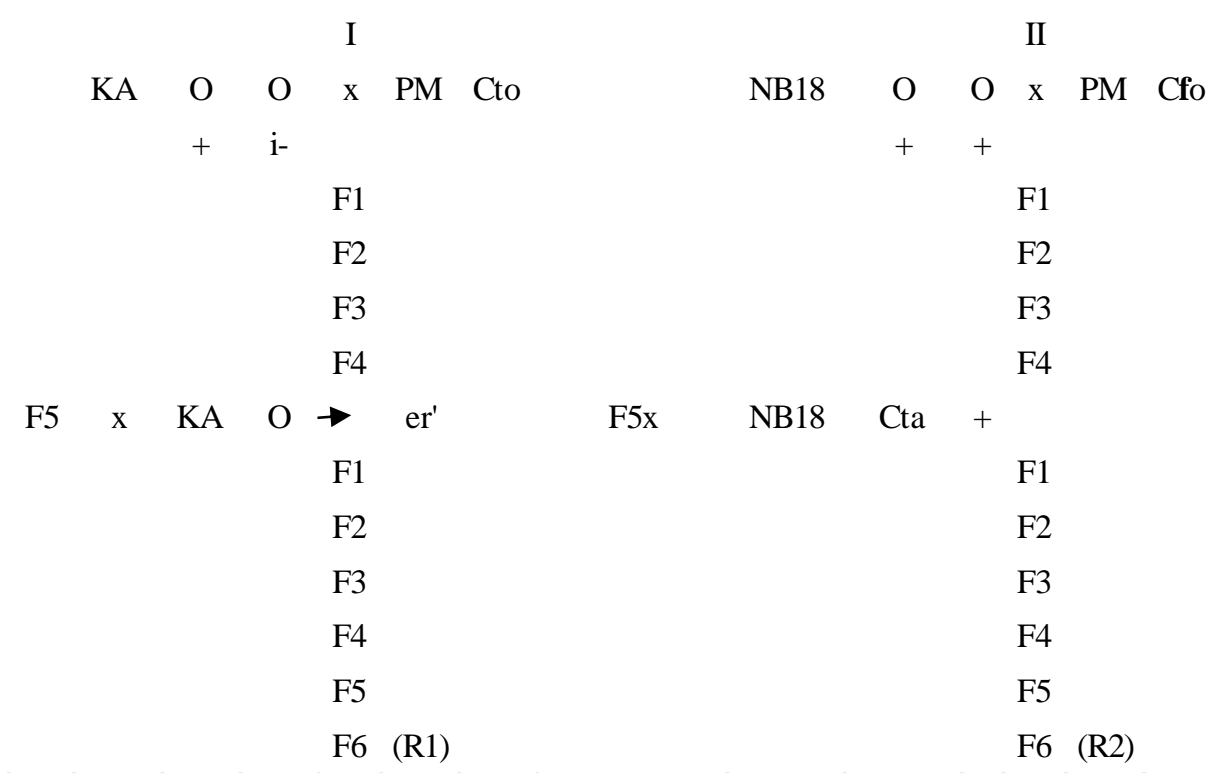

\subsection{Statistical Analysis}

Heterosis in $\mathrm{F}_{1}$ generations of crosses including $\mathrm{NB}_{18}$ and $\mathrm{PM}$ were determined over Mid-parental value (MPV) and Better parent value (BPV). Heterosis was determined as follows;

$\%$ Heterosis over MP $=(\mathrm{F} 1-\mathrm{MPV} / \mathrm{MPV}) \mathrm{X} 100$

$\%$ Heterosis over $\mathrm{BP}=(\mathrm{F} 1-\mathrm{BPV} / \mathrm{BPV}) \mathrm{X} 100$

Where;

MP: Mid Parent

BP: Better Parent 


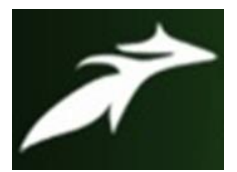

Manjula A. C. et al, International Journal of Advances in Agricultural Science \& Technology,

Vol.8 Issue.10, October-2021, pg. 7-16

ISSN: 2348-1358

Impact Factor: 6.057

NAAS Rating: 3.77

Significant test for heterosis was performed using standard ANOVA table. To test the generation effect on the rearing performance standard regressions of different parameters on the generation number were worked out. To compare the generation performance of crosses, the data were transformed into standard normal varieties. This is due to the fact that per second comparison of the absolute value does not show the inherent trend in the data.

\section{Results}

\subsection{Matured Larval Weight}

The $F_{1}$ hybrids of the cross KAxPM revealed a mean matured larval weight of $4.002 \pm 0.009$ which decreased in succeeding generations up to $F_{5}$ with mean matured larval weight $3.500 \pm 0.060$ gms. The $F_{5}$ females were backcrossed to the parent males. In the $F_{1}$ the matured larval weight was found to be $4.002 \pm 0.010$ and in succeeding generations it did show only marginal change it may be seen from the table 1 and Fig. 1, the curve shows the declining trend in two-way cross while in three way cross the trend is slightly changed. The line moves towards fixation.

Table 1: Performance of important silkworm character in two and three-way hybrid of KAxPM

\begin{tabular}{|c|c|c|c|}
\hline & Generations & Matured Larval Weight & Larval Duration \\
\hline \multirow{4}{*}{ KAxPM } & 1 & 1.5146 & 1.8594 \\
& 2 & 0.5795 & -0.0523 \\
& 3 & -0.4949 & -1.0182 \\
& 4 & -0.4914 & -0.6761 \\
& 5 & -1.1078 & -0.1127 \\
\hline F5 & 1 & 0.2540 & 0.7793 \\
(KAxPM)xKA & 2 & 0.7309 & 1.0489 \\
& 3 & -0.1939 & 0.7559 \\
& 5 & -0.7464 & -1.7520 \\
& 5 & -0.2055 & -0.8028 \\
& 5 & 0.1609 & -0.0293 \\
\hline
\end{tabular}

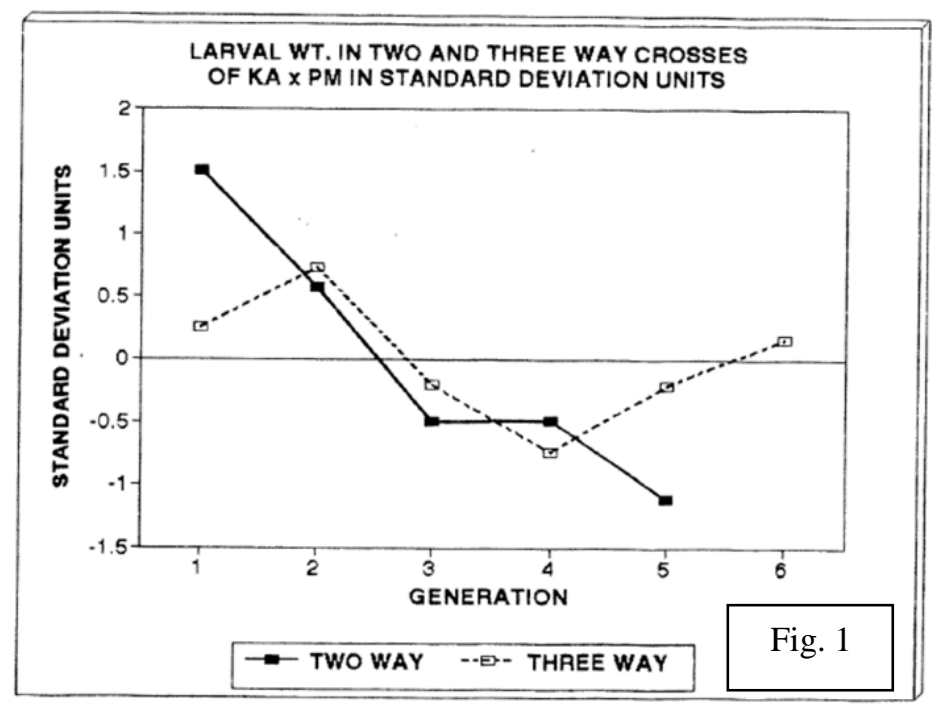




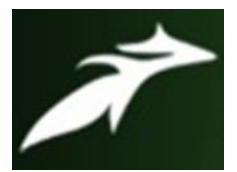

Manjula A. C. et al, International Journal of Advances in Agricultural Science \& Technology,

Vol.8 Issue.10, October-2021, pg. 7-16

ISSN: 2348-1358

Impact Factor: 6.057

NAAS Rating: 3.77

The $\mathrm{F}_{1}$ hybrids of the cross NB18xPM revealed a mean matured larval weight of $4.008 \pm 0.029 \mathrm{~g}$. It gradually decreased to $3.775 \pm 0.047$ in $\mathrm{F}_{5}$. The $\mathrm{F}_{5}$ females were backcrossed to the $\mathrm{NB}_{18}$ males with a mean matured larval weight of $4.113 \pm 0.087$. The larval weight increased to $4.047 \pm 0.066$ in $\mathrm{F}_{1}$. Later it, was slightly decreased and in $F_{5}$ and $F_{6}$ it was $4.009 \pm 0.087$ and $3.928 \pm 0.096$ showing the fixation of the trait leading to the isolation of the line.

From the table 2 and Fig. 2, it may be seen that same trend is observed for both two-way and three way crosses. However, the line showed the downward trend in the last generation. Regression of matured larval weight on generation number was significant for KA. This implies that environment has a significant role in the expression of this trait in KA whereas the role of environment is not significant in KA and PM. When the mean performance of KA $(2.9 \pm 1.43)$ with F5 (KA x PM) x KA (3.99 \pm 0.005$)$ was compared. The magnitude was high in hybrid (Tables 3 and 4). When the mean performance of $\mathrm{NB}_{18}(3.849 \pm 0.124)$ with F5 (NB18xPM) $\mathrm{x} \mathrm{NB}_{18}$ (3.928 \pm 0.096$)$ was compared, the magnitude was marginally higher in hybrid (Tables 5 and 6 ).

Table 2: Performance of important silkworm character in two and three-way hybrid of NBxPM

\begin{tabular}{|c|c|c|c|}
\hline & Generations & Matured Larval Weight (g) & Larval Duration (Days) \\
\hline \multirow{4}{*}{$\mathrm{NB}_{18} \mathrm{xPM}$} & 1 & 0.7984 & 1.5385 \\
& 2 & -0.1338 & 0.3541 \\
& 3 & -0.7656 & -1.2993 \\
& 4 & 0.4362 & -0.8419 \\
& 5 & -0.3352 & 0.2486 \\
\hline & 1 & 0.8526 & -0.3161 \\
$\left(\mathrm{NB}_{18} \mathrm{xPM}\right) \mathrm{N}$ NB1 & 2 & 0.1764 & 2.0142 \\
& 3 & 0.3575 & 0.0226 \\
& 5 & -1.1921 & -1.0071 \\
& 6 & 0.3897 & -0.7768 \\
& 5 & -0.5843 & 0.0632 \\
\hline
\end{tabular}

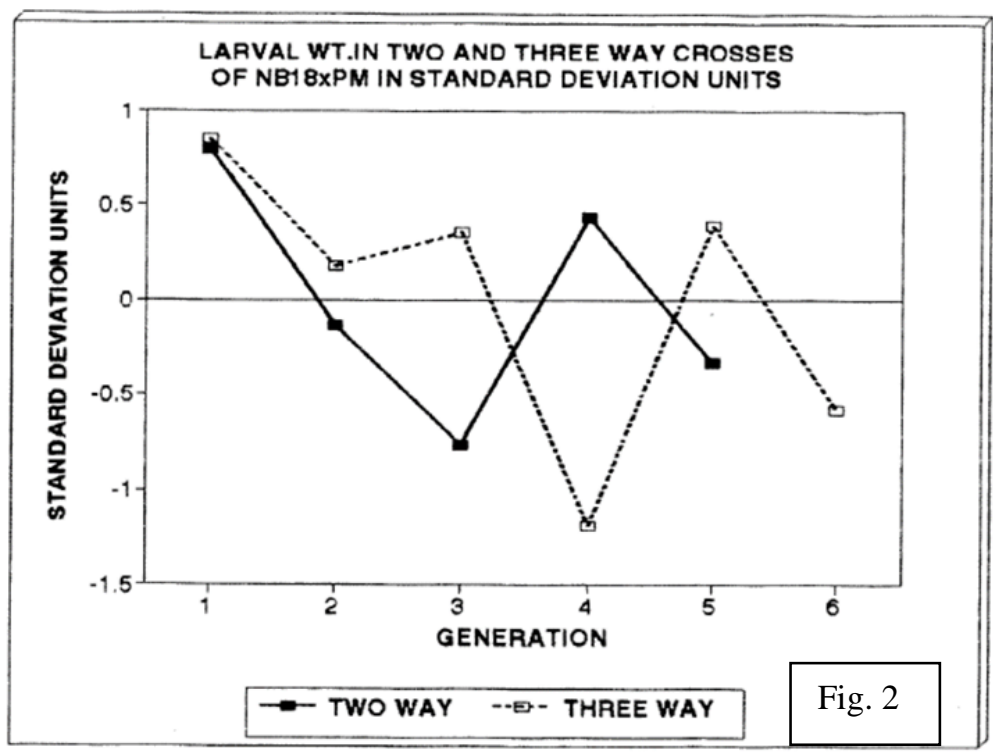




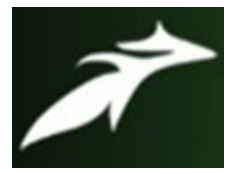

Manjula A. C. et al, International Journal of Advances in Agricultural Science \& Technology,

Vol.8 Issue.10, October-2021, pg. 7-16

ISSN: 2348-1358

Impact Factor: 6.057

NAAS Rating: 3.77

Table 3: Matured larval weight and larval duration in bivoltine silkworm race KA over 12 generations

\begin{tabular}{|c|c|c|}
\hline Generations & Matured Larval Weight (g) & Larval Duration (Days) \\
\hline 1 & $4.146 \pm 0.031$ & $27.250 \pm 0.068$ \\
\hline 2 & $3.956 \pm 0.049$ & $27.014 \pm 0.0196$ \\
\hline 3 & $3.848 \pm 0.121$ & $25.278 \pm 0.196$ \\
\hline 4 & $3.976 \pm 0.046$ & $24.917 \pm 0.122$ \\
\hline 5 & $3.975 \pm 0.119$ & $27.208 \pm 0.068$ \\
\hline 6 & $4.044 \pm 0.042$ & $27.431 \pm 0.0078$ \\
\hline 7 & $4.066 \pm 0.050$ & $27.000 \pm 0.068$ \\
\hline 8 & $3.879 \pm 0.049$ & $26.875 \pm 0.034$ \\
\hline 9 & $4.020 \pm 0.079$ & $24.944 \pm 0.085$ \\
\hline 10 & $3.694 \pm 0.084$ & $25.083 \pm 0.589$ \\
\hline 11 & $3.799 \pm 0.098$ & $26.986 \pm 0.070$ \\
\hline 12 & $3.849 \pm 0.124$ & $27.667 \pm 0.472$ \\
\hline
\end{tabular}

Values are expressed as Mean \pm SD

Table 4: Matured larval weight and larval duration in of silkworm hybrid F (KAxPM) x KA in 6 generations

\begin{tabular}{|c|c|c|}
\hline Generations & Matured Larval Weight (g) & Larval Duration (Days) \\
\hline F1 & $4.002 \pm 0.010$ & $27.042 \pm 0.034$ \\
\hline F2 & $4.030 \pm 0.052$ & $27.361 \pm 0.039$ \\
\hline F3 & $3.977 \pm 0.087$ & $27.014 \pm 0.020$ \\
\hline F4 & $3.945 \pm 0.059$ & $24.042 \pm 0.034$ \\
\hline F5 & $3.976 \pm 0.040$ & $25.167 \pm 0.034$ \\
\hline F6 & $3.997 \pm 0.005$ & $26.083 \pm 0.059$ \\
\hline
\end{tabular}

Values are expressed as Mean \pm SD

Table 5: Matured larval weight and larval duration in bivoltine silkworm race $\mathrm{NB}_{18}$ over 12 generations

\begin{tabular}{|c|c|c|}
\hline Generations & Matured Larval Weight (g) & Larval Duration (Days) \\
\hline 1 & $4.119 \pm 0.088$ & $29.056 \pm 0.051$ \\
\hline 2 & $4.144 \pm 0.123$ & $27.500 \pm 0.117$ \\
\hline 3 & $3.721 \pm 0.079$ & $24.736 \pm 0.070$ \\
\hline 4 & $3.916 \pm 0.081$ & $25.139 \pm 0.085$ \\
\hline 5 & $4.133 \pm 0.087$ & $27.111 \pm 0.051$ \\
\hline 6 & $3.931 \pm 0.051$ & $28.139 \pm 0.085$ \\
\hline 7 & $3.839 \pm 0.159$ & $29.125 \pm 0.068$ \\
\hline 8 & $4.039 \pm 0.044$ & $27.472 \pm 0.109$ \\
\hline 9 & $4.020 \pm 0.079$ & $24.944 \pm 0.085$ \\
\hline 10 & $3.694 \pm 0.084$ & $25.083 \pm 0.589$ \\
\hline 11 & $3.799 \pm 0.098$ & $26.986 \pm 0.070$ \\
\hline 12 & $3.849 \pm 0.124$ & $27.667 \pm 0.472$ \\
\hline
\end{tabular}

Values are expressed as Mean \pm SD 


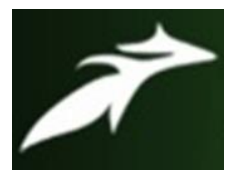

Manjula A. C. et al, International Journal of Advances in Agricultural Science \& Technology,

Vol.8 Issue.10, October-2021, pg. 7-16

ISSN: 2348-1358

Impact Factor: 6.057

NAAS Rating: 3.77

Table 6: Matured Larval Weight and Larval Duration of silkworm hybrid F (NBxPM) x NB in 6 generations

\begin{tabular}{|c|c|c|}
\hline Generations & Matured Larval Weight (g) & Larval Duration (Days) \\
\hline 1 & $4.047 \pm 0.066$ & $26.00 \pm 0.577$ \\
\hline 2 & $3.991 \pm 0.009$ & $28.01 \pm 0.064$ \\
\hline 3 & $4.006 \pm 0.091$ & $26.00 \pm 0.024$ \\
\hline 4 & $3.878 \pm 0.058$ & $24.23 \pm 0.072$ \\
\hline 5 & $4.009 \pm 0.087$ & $25.05 \pm 0.064$ \\
\hline 6 & $3.928 \pm 0.096$ & $26.01 \pm 0.024$ \\
\hline
\end{tabular}

Values are expressed as Mean \pm SD

From Tables 7 and 8, it may be seen that degree of heterosis calculated over MP (33.449) and BP (-3.475) is significant in $\mathrm{F}_{1}$ generation. It was significant over BP and MP in three way cross hybrids also. For NB ${ }_{18} \times \mathrm{PM}$ hybrids it may be seen from Table 9, the degree of heterosis is significant over MP (32.005) only. In the three ways cross it was significant.

Table 7: Heterotic effects in different economic characters of silkworm hybrids KAxPM

\begin{tabular}{|c|c|c|}
\hline KAXPM & Matured Larval Weight (g) & Larval Duration (Days) \\
\hline MP & $34.449^{*}$ & $-11.014^{*}$ \\
\hline BP & $-3.473^{*}$ & $-1.580^{*}$ \\
\hline
\end{tabular}

*Significance at $5 \%$

Table 8: Heterotic effects in different economic characters of silkworm hybrids F5 (KAXPM) X KA

\begin{tabular}{|c|c|c|}
\hline & Matured Larval Weight (g) & Larval Duration (Days) \\
\hline MP & $7.02^{*}$ & 2.70 \\
\hline BP & $0.687^{*}$ & -0.612 \\
\hline
\end{tabular}

*Significance at $5 \%$

Table 9: Heterotic effects in different economic characters of silkworm hybrids $\mathrm{NB}_{18} \mathrm{XPM}$

\begin{tabular}{|c|c|c|}
\hline $\mathrm{Bt}>$ & Matured Larval Weight (g) & Larval Duration (Days) \\
\hline $\mathrm{MP}$ & $32.005 * \mathrm{n}$ & $-10.246 * \mathrm{n}$ \\
\hline $\mathrm{BP}$ & -2.695 & $-4.111 * \mathrm{n}$ \\
\hline
\end{tabular}

*Significance at $5 \%$

\subsection{Larval Duration}

The $\mathrm{F}_{1}$ hybrids of the cross KAxPM revealed a mean larval duration of $26.8 \pm 0.071$ days in F1 which decreased in succeeding generations and in $\mathrm{F}_{5}$ it was $25.4 \pm 0,034$ days. The $\mathrm{F}_{5}$ females were backcrossed to the parent $\mathrm{KA}$ with a mean larval duration of $27.042 \pm 0.034$ days, in $F_{1}$ it was $24.04 \pm 0.034$ days in $F_{4}$ and 26 days in F6 (tables 10 and 4). Further it may be seen from the table 1 and Fig. 3, expressed in terms of standard deviation units. The line declines and it shows upward trend in later generations. The same trend is seen for the three way cross also.

Table 10: Matured Larval Weight and larval Duration of silkworm hybrid KAxPM in 5 generations

\begin{tabular}{|c|c|c|}
\hline Generations & Matured Larval Weight (g) & Larval Duration (Days) \\
\hline F1 & $4.002 \pm 0.004$ & $26.819 \pm 0.071$ \\
\hline F2 & $3.823 \pm 0.081$ & $25.500 \pm 0.059$ \\
\hline F3 & $3.618 \pm 0.079$ & $24.833 \pm 0.068$ \\
\hline F4 & $3.618 \pm 0.088$ & $25.069 \pm 0.039$ \\
\hline F5 & $3.500 \pm 0.060$ & $25.458 \pm 0.034$ \\
\hline
\end{tabular}

Values are expressed as Mean \pm SD 


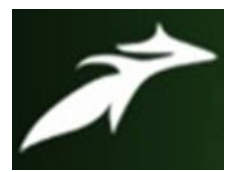

Manjula A. C. et al, International Journal of Advances in Agricultural Science \& Technology,

Vol.8 Issue.10, October-2021, pg. 7-16

ISSN: 2348-1358

Impact Factor: 6.057

NAAS Rating: 3.77

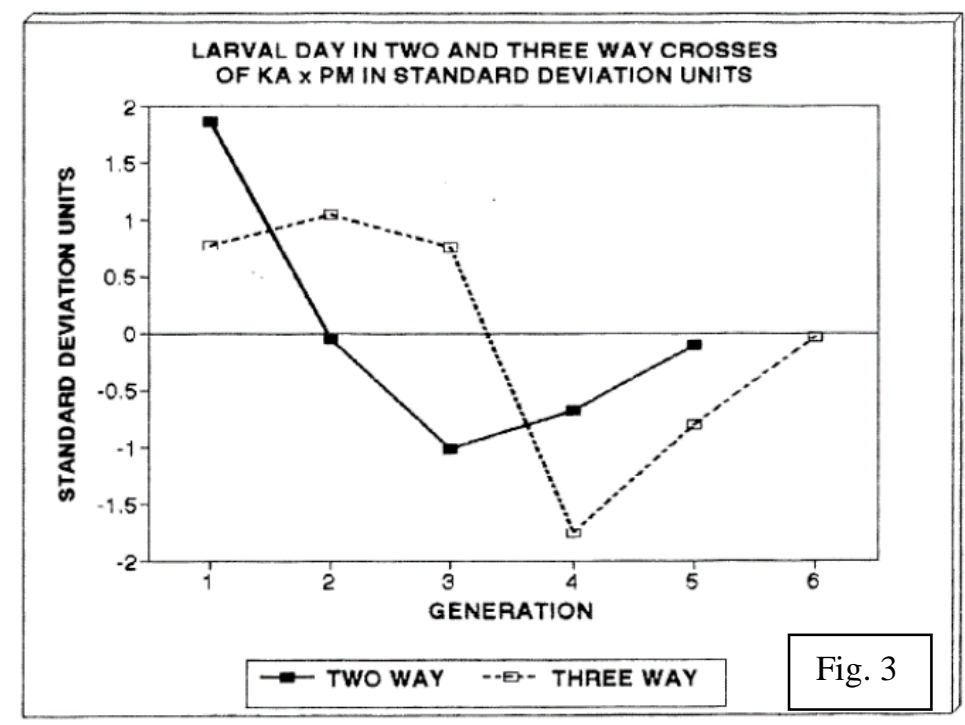

The $\mathrm{F}_{1}$ hybrids of the cross $\mathrm{NB}_{18} \mathrm{xPM}$ revealed a mean larval duration of $27.21 \pm 0.048$ days. It decreased to $24.13 \pm 0,083$ days in $\mathrm{F}_{3}$ and in $\mathrm{F}_{5}$ to $26.13 \pm 0,301$ days. The $\mathrm{F}_{5}$ females were backcrossed to the parent $\mathrm{NB}_{18}$. In $\mathrm{F}_{1}$ the larval duration was $24.23 \pm 0.072$ days and it varied in succeeding generations and in $\mathrm{F}_{6}$ it was 26.01 \pm 0.024 days (tables 11 and 6).

Table 11: Matured larval weight and larval duration of silkworm hybrid NB1axPM in 5 generations

\begin{tabular}{|c|c|c|}
\hline Generations & Matured Larval Weight (g) & Larval Duration (Days) \\
\hline 1 & $4.008 \pm 0.029$ & $27.21 \pm 0.048$ \\
\hline 2 & $3.816 \pm 0.108$ & $26.11 \pm 0.042$ \\
\hline 3 & $3.687 \pm 0.449$ & $24.13 \pm 0.083$ \\
\hline 4 & $3.933 \pm 0.048$ & $25.01 \pm 0.042$ \\
\hline 5 & $3.775 \pm 0.047$ & $26.13 \pm 0.301$ \\
\hline
\end{tabular}

Values are expressed as Mean \pm SD

Further, it is seen from Fig. 4 in two-way cross, the curve shows declining trend up to $\mathrm{F}_{3}$ and later shows upward trend. The same trend is seen for three-way cross also. Regression of larval duration on generation number was not significant in any of the parents. This implies that environment has not played any role on the

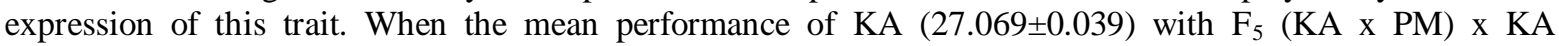
$(26.08 \pm 0.05)$ was compared. The hybrid has shorter larval duration (Tables 3 and 4). When the mean performance of $\mathrm{NB}_{18}(27.6 \pm 0.478)$ with $\mathrm{F}_{5}\left(\mathrm{NB}_{18} \times \mathrm{PM}\right) \times \mathrm{NB}_{18}$ (26.01) was compared, the magnitude was marginally higher in hybrid (Tables 5 and 6). It may be seen from Table 7 that the degree of heterosis calculated over MP value was significant (-11.014) and BP also was found to be significant (1.580). For three way cross hybrids the degree of heterosis was non-significant over MP and BP (Table 8). For hybrids of the cross $\mathrm{NB}_{18} \mathrm{xPM}$, the degree of heterosis was significant over MP (-10.246) and also over BP (-4.111). 


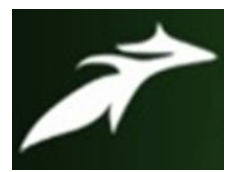

Manjula A. C. et al, International Journal of Advances in Agricultural Science \& Technology, Vol.8 Issue.10, October-2021, pg. 7-16

ISSN: 2348-1358

Impact Factor: 6.057

NAAS Rating: 3.77

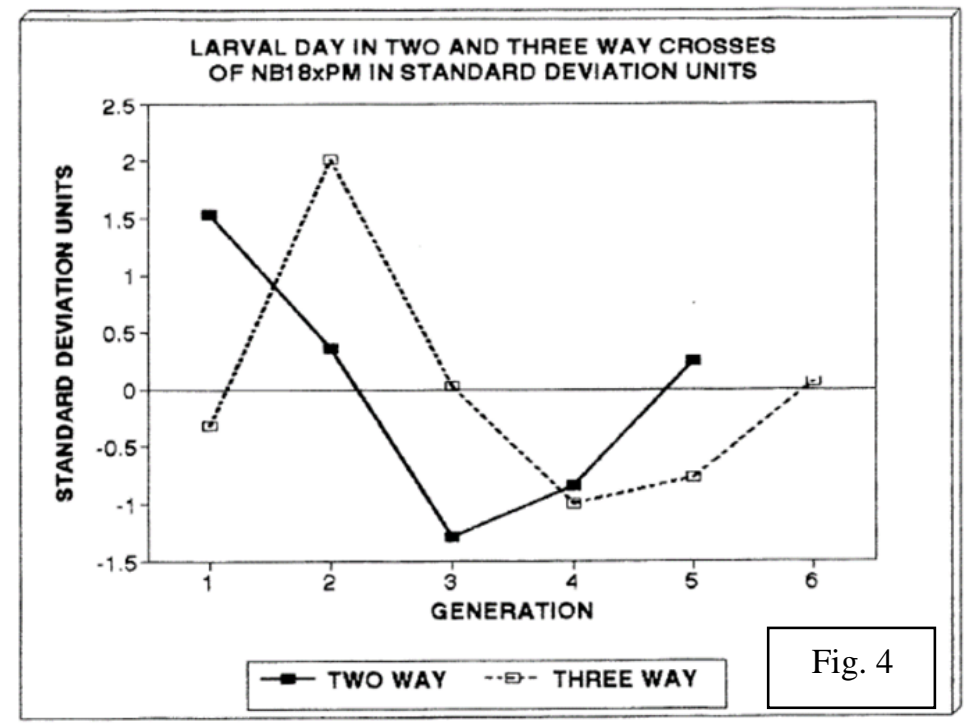

\section{Discussion}

Hybridization as a procedure has been practiced since the beginning of civilization for improving any breed of animal or plant for better performance than the pure races. It provides choice for genetic manipulation for the selection of new and better gene combinations. Utilizing the known genotypes, choice of mating systems and judicious method of selection is of vital importance in the conventional breeding methods such as line breeding and cross breeding. Cross breeding is more dependable than line breeding for evolution of silkworm races. Some races are good in some characters and some are poor in some characters. Cross breeding involves two or more races in order to get desirable characters. Three pure lines with known genotype were used to obtain new promising lines. Multivoltine race Pure Mysore spinning yellow pointed cocoon shows resistance to diseases and is known for its less silk yield. ${ }^{11}$ Tropical bivoltines Kalimpong-A (KA) spinning oval white cocoon and $\mathrm{NB}_{18}$ spinning dumbell white cocoon are known for their higher silk yield and are comparatively less resistant to diseases and adverse environmental conditions. ${ }^{12}$

In the present study the author used bivoltine females and multivoltine males. The crosses were made initially and backcrossed to $\mathrm{F}_{5}$ generations. Analysis of the metric traits viz. matured larval weight and larval duration revealed the manifestation of varied degrees of heterosis over mid parent and better parent. Owing to the simultaneous segregation of a large number of genes in conjugation with the influence of environmental effects. For instance, economic traits like matured larval weight and larval duration show much statistical variation with respect to fixation of the traits. Selection is made to choose intermediate sized cocoons from the batches of high ERR as these individuals are expected to possess maximum fitness value. ${ }^{13}$ Accordingly inbreeding and selection over generations resulted in favorable combinations of desired alleles in the progenies leading to the expression of statistically non-significant differences for the metric traits under studies at later generation indicating their fixation in the isolated lines.

The results of the presentinvestigation with regard to the manifestation of heterosis are in agreement with the findings of Osawa and Harada (1944). ${ }^{14}$ Harada $(1956,1961)$ who have pointed that greater the midparent value, lesser will be the effect of heterosis. Overall performance of backcross hybrids are observed to be better than biparental hybrids (KAxPM or $\mathrm{NB}_{18} \mathrm{xPM}$ ) due to the fact that backcross hybrids have $75 \%$ of the genetic structure resembles that of either $\mathrm{KA}$ or $\mathrm{NB}_{18}$ as the case may be. 


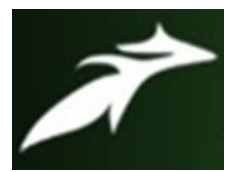

Manjula A. C. et al, International Journal of Advances in Agricultural Science \& Technology, Vol.8 Issue.10, October-2021, pg. 7-16

ISSN: 2348-1358

Impact Factor: 6.057

NAAS Rating: 3.77

While the biparental hybrid contains only $50 \%$ of $\mathrm{NB}_{18}$ or KA. ${ }^{15,16}$ However, degree of heterosis is more prominent in Biparental cross than backcross hybrids. ${ }^{17}$

The performance of a race or a strain is a function of both heredity potentials of its population and the extent to which such potentialities are permitted to be realised in the environment to which they are exposed. Environment is dynamic and can bring about profound changes in the physical and biotic factor.

\section{Conclusion}

The results of our study delineated that the mean performance of characters viz. matured larval weight and larval duration over generations do not increase or decrease in a simple regular fashion but fluctuates erratically. The reason for this variation may be attributable to random genetic drift, sampling errors in estimation of generation means, selection pressure, environmental factors. Hence, breeding variation due to random drift and sampling errors could be reduced by increasing the number sampled and selected.

\section{References}

[1]. Tazima Y. Evolution, differentiation and breeding of the silkworm. The silk road, past and present. The silkworm and its relatives contributes. Bull. Sericult Exp. Sta. 1944; 11: 525.

[2]. Hirobe, T. Evolution, differentiation and breeding of silkworm the silk road, past and present. XII Int. Cong. Genetics, Tokyo, Genetics in Asian Countries. 1968; 2:25-36.

[3]. Yokoyama T. Silkworm selection and hybridisation. genetics in relation to insect management. 1979 ; $71-83$.

[4]. Benchamin KV. Studies on the reciprocal crosses of multivoltine and bivoltine breeds in silkworm Bombyx mori L. with special reference to the use of bivoltine hybrids as a male parent. Indian J. Seric.1988;27(1):27-34.

[5]. Narasimhanna MN, Gururaja NK. Contributions to the genetics of silkworm B. mori J. Mys. Univ. $1965 ; 18(1 \& 2): 38-43$.

[6]. Sinha AK, Sinha USP, Shivaraju K, Sinha, SS. Phosphatase activity in tasar silkworm Antheraea mylitta D. during its larval and pupal development. Indian J. Serie. 1991;30(1):91-92.

[7]. Subramanya G. Ecogenetic approach for determination of high yielding breeds of silkworm B. mori L. Ph.D. Thesis, Univ. of Mysore, Mysore, India. 1985

[8]. Raju PJ, Krishnamurthy NB. Evolving of a multivoltine white with short larval duration in silkworm Bombyx mori (L.). Sericologia. 1987;27(1):65-76.

[9]. Narasimhanna MN. Manual on silkworm egg production. 1988.

[10]. Krishnaswamy S. Improved techniques of bivoltine rearing, CSB Publication. 1978.

[11]. Nanavathy. Silk from grub to glamour CSB Publication, Bombay. 1965.

[12]. Sengupta K. Bivoltine rearing in the plains and plateaus of South India. Indian Silk. 1988;27(7):25-7.

[13]. Robertson A. Artificial selection in plants and animals. Proceedings of the Royal Society of London. Series B. Biological Sciences. 1966;164(995):341-9.

[14]. Osawa K, Harada C. Studies on the F1 hybrids of the silkworm III On the effect of heterosis. Bull. Seric. Expt. Stn. Japan. 1944; 12:183-211.

[15]. Harada C. On the relation between commercial characters and their F1 hybrids in Bombyx mori. InProc. Int. Genet. Symp. 1956: pp352-356.

[16]. Harada C. Heterosis of the quantitative character in the silkworm Bull. Seri. Exp. Station, 1961;17(1): 50-52.

[17].Falcomer DS. Introduction to quantitative inheritance 2nd ed. Layman, London. 1981.pp340. 